\title{
Ultrastructure of Capillaria hepatica (Syn. Calodium hepatica) Isolated from the Liver of Mouse Infected with Artificially Embryonated Eggs Collected from House Rats (Rattus norvegicus)
}

\author{
Byoung-Hoon Min ${ }^{1,3}$, Haeng-Sook Lee ${ }^{1}$, Soo-Jin $\mathrm{Kim}^{2, *}$, Kyoung-Hwan Joo ${ }^{1, *}$ \\ ${ }^{1}$ Department of Parasitology and the Institute of Travel Medicine, Korea University College of Medicine, Seoul 136-705, Korea \\ ${ }^{2}$ Department of Life Science, College of Natural Science, Hallym University, Chuncheon 200-702, Korea \\ ${ }^{3}$ Xenotransplantation Research Center, Seoul National University College of Medicine, Seoul 110-799, Korea
}

*Correspondence to:

Kim SJ,

Tel: +82-33-248-2091

Fax: +82-33-256-3420

E-mail: sjkim@hallym.ac.kr

Joo $\mathrm{KH}$,

Tel: +82-2-920-6161

Fax: +82-2-924-4905

E-mail: kyhwjoo@korea.ac.kr

Received November 19, 2013

Revised December 13, 2013

Accepted December 23, 2013
Capillaria hepatica (syn. Calodium hepatica) is a parasite found mainly in rodent liver. But, it has also been found in a wide variety of mammals, including humans. This worm is unique as it is the only nematode parasite that is embedded in the liver parenchyma of the host even during the adult stage of the life cycle. They produce eggs that elicit a marked granulomatous reaction that eventually destroys the worms. Fibrosis and lymphoplasmacytic inflammatory infiltration are often observed around adult nematodes embedded in the liver parenchyma of the host. For this reason, complete isolation of this slender worm and observation of the intact ultrastructure is very difficult. In this study, 10 intact whole worms ( $C$. hepatica) were isolated from the liver of 3-week-old mouse after inoculation of artificially embryonated eggs collected from house rats (Rattus norvegicus). Their external structure of was observed with light and scanning electron microscopy. The length of the isolated female and male C. hepatica was approximately $69.60 \mathrm{~mm}$ and 36.92 $\mathrm{mm}$, respectively. More detailed ultrastructure, including bacillary band, eggs and vulva in female and spicule and spicule sheath in male C. hepatica was also described.

Key Words: Capillaria hepatica, Genital organ, Spicule, Scanning electron microscopy

\section{INTRODUCTION}

Capillaria hepatica (syn. Calodium hepatica; Bancroft, 1893) is a parasitic nematode living in the liver of rodents and other mammals such as rabbits, dogs, cats, cattle, and humans (Singleton et al., 1991; Roberts et al., 1996; Anderson, 2000; Nabi et al., 2007). About 30 cases of human infections have been reported from Asia, Africa, Europe, North and South America, and Oceania including United States of America, Japan, and Korea (McQuown, 1950; Choe et al., 1993; Kohatsu et al., 1995; Fuehrer et al., 2011).

Rat species of the genus Rattus are main primary host of $C$. hepatica and infection rates of up to $100 \%$ have been reported (Farhang-Azad, 1977; Singleton et al., 1991; Ceruti et al., 2001; Claveria et al., 2005). In addition to the principal hosts, rodents, other mammals can be infected through ingestion of water or food contaminated by infectious embryonated eggs. C. hepatica does not require an intermediate host in their life cycle and thus death of the host is only way to release the embedded eggs. When the embryonated eggs are ingested by a new host, they develop into the adult worm in the liver of the host within approximately 20 days. The natural lifespan of the adult female worm is approximately 60 days (Spratt \& Singleton, 2001; Kim et al., 2007) and that of male

This work was supported by a Korea University grant.

@ This is an open-access article distributed under the terms of the Creative Commons Attribution Non-Commercial License (http://creativecommons.org/licenses/by-nc/3.0) which permits unrestricted noncommercial use, distribution, and reproduction in any medium, provided the original work is properly cited.

Copyrights @ 2013 by Korean Society of Microscopy 
worm is approximately 40 days (Luttermoser, 1938; Wright, 1961). To date, complete isolation of the adult worm and observation of intact ultrastructure has been very difficult, because the slender and hair-like worms are embedded in the liver parenchyma of the host during the adult stage. For these reasons, reports on the morphological study of external structure of $C$. hepatica are limited.

In this study, 10 intact whole worms were isolated from the liver of 3-week-old mouse after inoculation of artificially embryonated eggs collected from house rats (Rattus norvegicus). The external and fine structures of genital organ were examined with light and scanning electron microscopy (SEM).

\section{MATERIALS AND METHODS}

\section{Experimental Animals and Collection of Capillaria hepatica Eggs}

House rats ( $R$. norvegicus) were taken from an urban marketplace in Seoul, Korea. The liver of house rats infected with $C$. hepatica was homogenized with a sterilized slide glass. Then, the eggs were collected with a micropipette. Collected eggs were embryonated by incubating at $37^{\circ} \mathrm{C}$ for 5 weeks in $0.5 \%$ formalin solution. Individual 8-week-old male BALB/c mouse was inoculated with 1,000 embryonated eggs $(n=10$, Samtako, Osan, Korea) through oral zonde and mice were bred for 3-weeks.

\section{Isolation of Capillaria hepatica}

Whole worms were isolated from the mouse liver after inoculation of the embryonated eggs using enzyme digestion methods. Briefly, liver tissue was homogenized with a sterilized slide glass and incubated for 4 to 5 hours in phosphate buffer solution containing type IV collagenase and antibiotics $(\mathrm{pH}$ 7.4) at $37^{\circ} \mathrm{C}$. The homogenized livers were washed with normal saline solution including antibiotics at $37^{\circ} \mathrm{C}$ and released worms were isolated using a pair of tweezers.

\section{Microscopic Observation}

Isolated $C$. hepatica was fixed with $10 \%$ buffered neutral formalin, dehydrated, and then mounted on the slide glass for light microscope observation. External structures of the worm were observed with a light microscope and the length and width of the isolated worm was measured with MetaMorph software (Universal Imaging Co., West Chester, PA, USA). For $\mathrm{H} \& \mathrm{E}$ staining, liver was fixed in $10 \%$ neutral formalin and embedded in paraffin according to standard protocol. Four $\mu \mathrm{m}$-thick liver section was deparaffinized and then stained with H\&E. For SEM observation, the isolated C. hepatica were fixed with $1 \%$ paraformaldehyde- $1 \%$ glutaraldehyde ( $\mathrm{pH} 7.4$ ) and $2 \%$ osmium tetroxide. Fixed samples were dehydrated in a graded ethanol series and treated with isoamyl acetate. Pretreated samples were dried with a critical point dryer (HCP2; Hitachi, Tokyo, Japan) and the surface was coated with gold in a vacuum using an ion coater (IB-III; Eiko, Tokyo, Japan). Prepared samples were observed with a SEM (S-2500; Hitachi).

\section{RESULTS}

When the extracted liver harboring C. hepatica was examined under a light microscope, several white clusters consisting of $C$. hepatica and eggs were easily observed and the hepatomegaly around the worms was noticeable. Clusters, measured 2 to 4


Fig. 1. Light micrograph of mouse liver at 3 weeks after embryonated Capillaria hepatica egg infection. (A) C. hepatica was embedded in the liver parenchyma surrounded by fibroblasts and macrophages. (B) The intestine (I), uterus (U), ovary (O), and two bacillary bands (Ba) were observed. Scale bars $=100 \mu \mathrm{m}$. 
$\mathrm{mm}$ in diameter, were scattered on the surface of the mouse liver. Numerous fibroblasts and macrophages were observed around the clusters in histological sections of infected mouse liver (Fig. 1A and B).
The length of the isolated female and male C. hepatica was approximately $69.60 \mathrm{~mm}$ and $36.92 \mathrm{~mm}$, respectively (Fig. 2). Female $C$. hepatica had a thin and pointed anterior end (Fig. $3 \mathrm{~A})$. Many oval shaped eggs (54 $\mu \mathrm{m}$ long and $31 \mu \mathrm{m}$ wide)
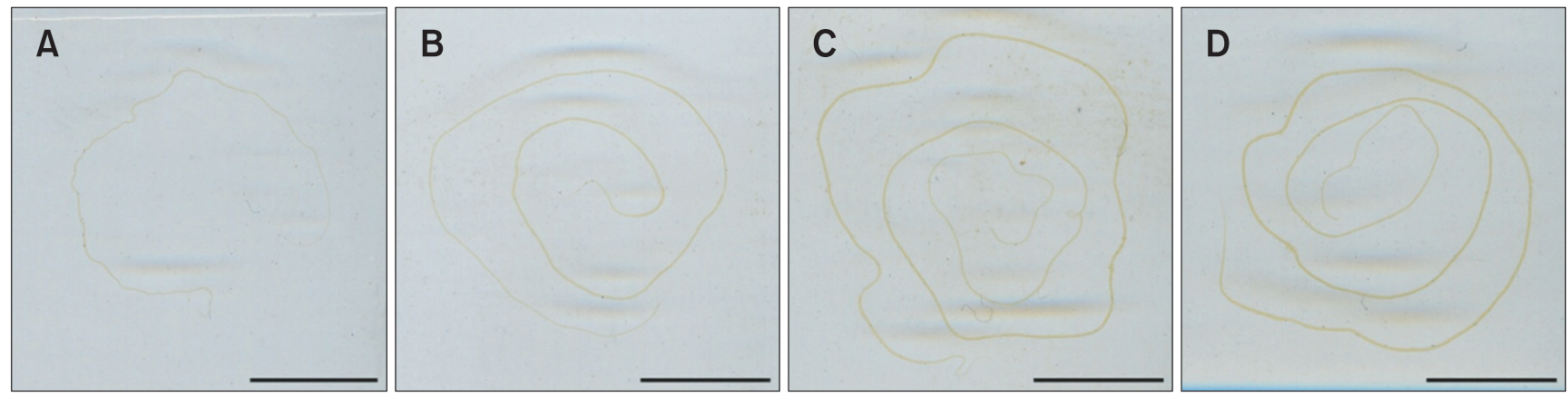

Fig. 2. Whole Capillaria hepatica isolated from the liver of mouse. Ten mice were experimentally infected with embryonated eggs of $C$. hepatica and livers were extracted at 3 weeks after infection. (A, B) Male worm. (C, D) Female worm. Scale bars $=5 \mathrm{~mm}$.
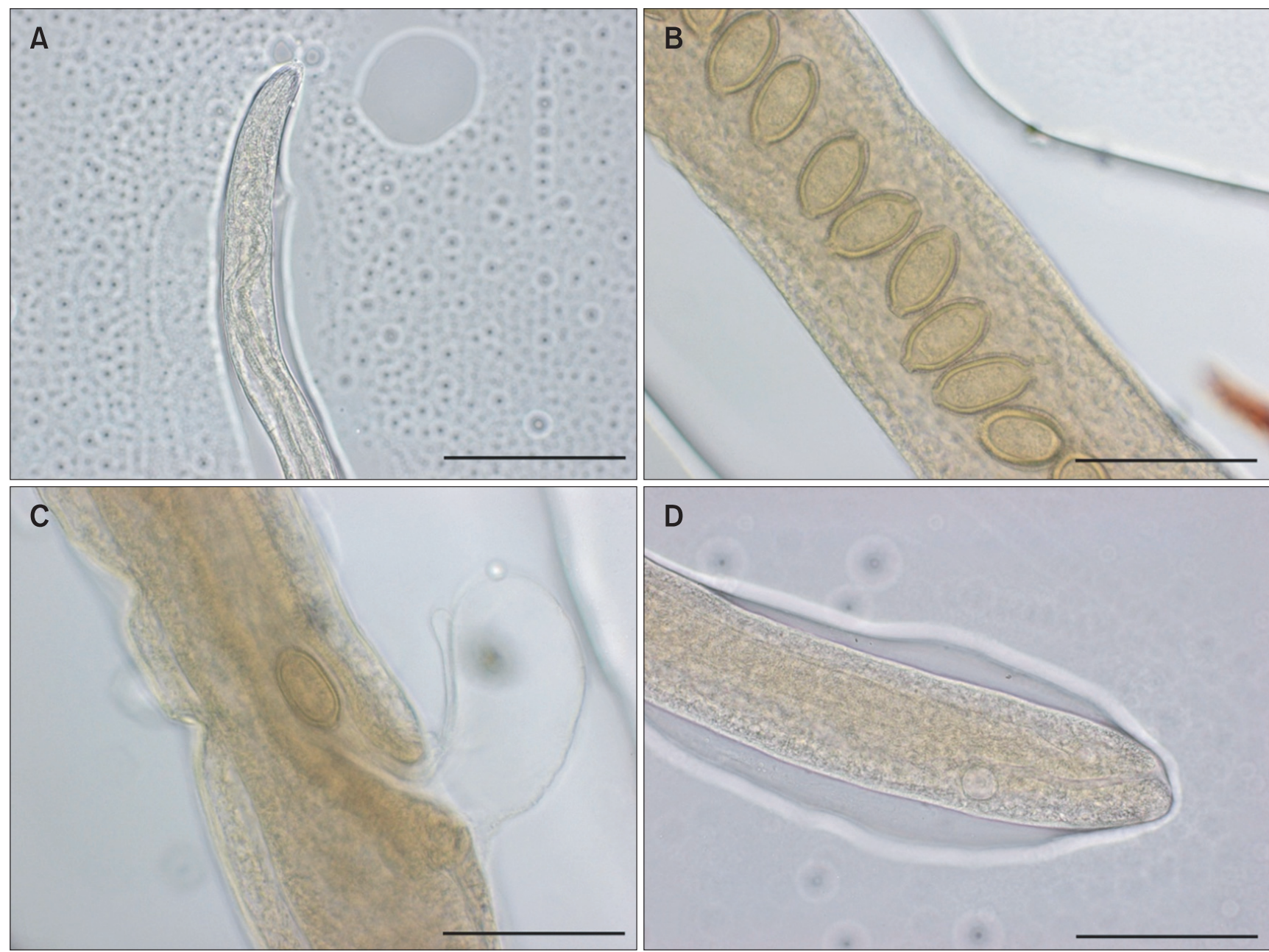

Fig. 3. Light micrograph of female Capillaria hepatica. (A) Anterior region. (B) Mid region of the worm containing unembryonated eggs in uterus. Vulva region of the female worm showing postvulval uterine sac (egg sac) projected from the worm (C) and posterior region (D). Scale bars=100 $\mu \mathrm{m}$. 
were observed in the uterus (Fig. 3B) and a pore like vulva was opened to outside in the posterior ventral region of the worm (Fig. 3C). The posterior end of female worms had a bluntly conical structure and was about 2.5 times wider than the anterior region (Fig. 3D).

The shape of anterior region of the male worm was similar to that of the female and had a thin and pointed end (Fig. 4A). A funnel-shaped spicular sheath was protruded from
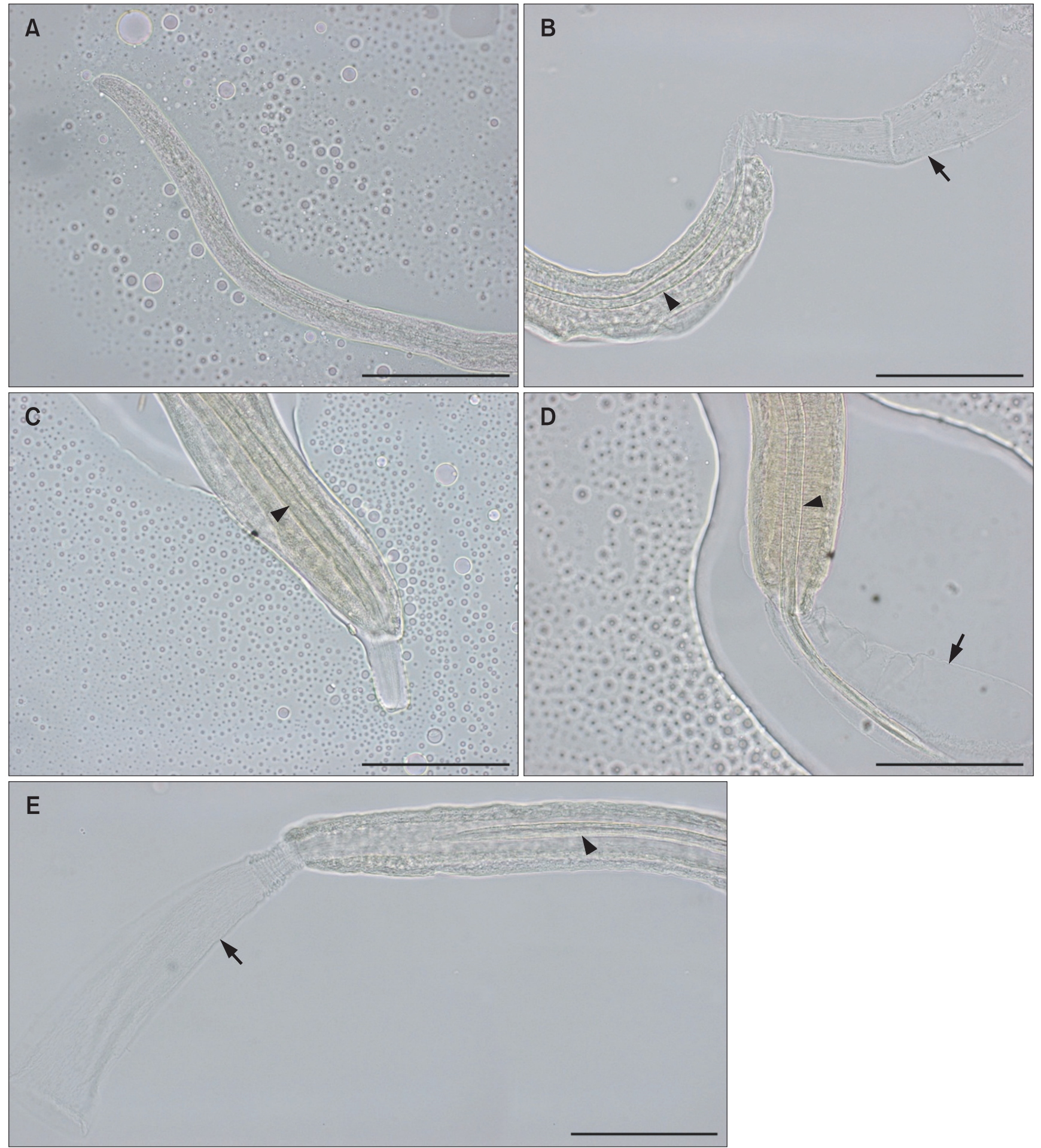

Fig. 4. Light micrograph of male Capillaria hepatica. (A) Anterior region. (B E) Posterior region and genital organ. Spicule (arrowheads) and spicular sheath (arrows). Scale bars $=100 \mu \mathrm{m}$. 
the posterior end (Fig. 4B). A projected spicule $(246.49 \mu \mathrm{m}$ long and $10.59 \mu \mathrm{m}$ wide) was observed at the end of the male worm. Several interesting patterns were observed in the morphological characteristics of the spicule and spicular sheath. First, a spicule protruded about $40 \mu \mathrm{m}$ from the posterior end (Fig. 4C). Second, a spicule of about $318 \mu \mathrm{m}$ in length was wrapped by the spicular sheath (Fig. 4D). Third, spicular sheath was funnel-shaped and protruded about 230 $\mu \mathrm{m}$ from the posterior end. Spicule was also occasionally located in the inner-cavity of the worm (Fig. 4E).

When the worm was examined by SEM, the anterior end was mostly thin (less than $10 \mu \mathrm{m}$ ) (Fig. 5A), and the width of the anterior and posterior regions was approximately 24.68 $\mu \mathrm{m}$ and $71.23 \mu \mathrm{m}$, respectively in the female $C$. hepatica. The anterior region has transverse striations at the interval of about $0.7 \mu \mathrm{m}$. The posterior end was tapered to a rounded end with an excretory pore (Fig. 5B). Mid region of the female worm was about $84.26 \mu \mathrm{m}$ thick and had a pair of bacillary bands with the bacillary pore located on the surface of the worm (Fig. $5 \mathrm{C}$ ). A pore-like vulva (about $8 \mu \mathrm{m}$ in diameter) was observed in the posterior ventral region of the worm (Fig. 5D). In addition to the vulva, the bacillary pores were
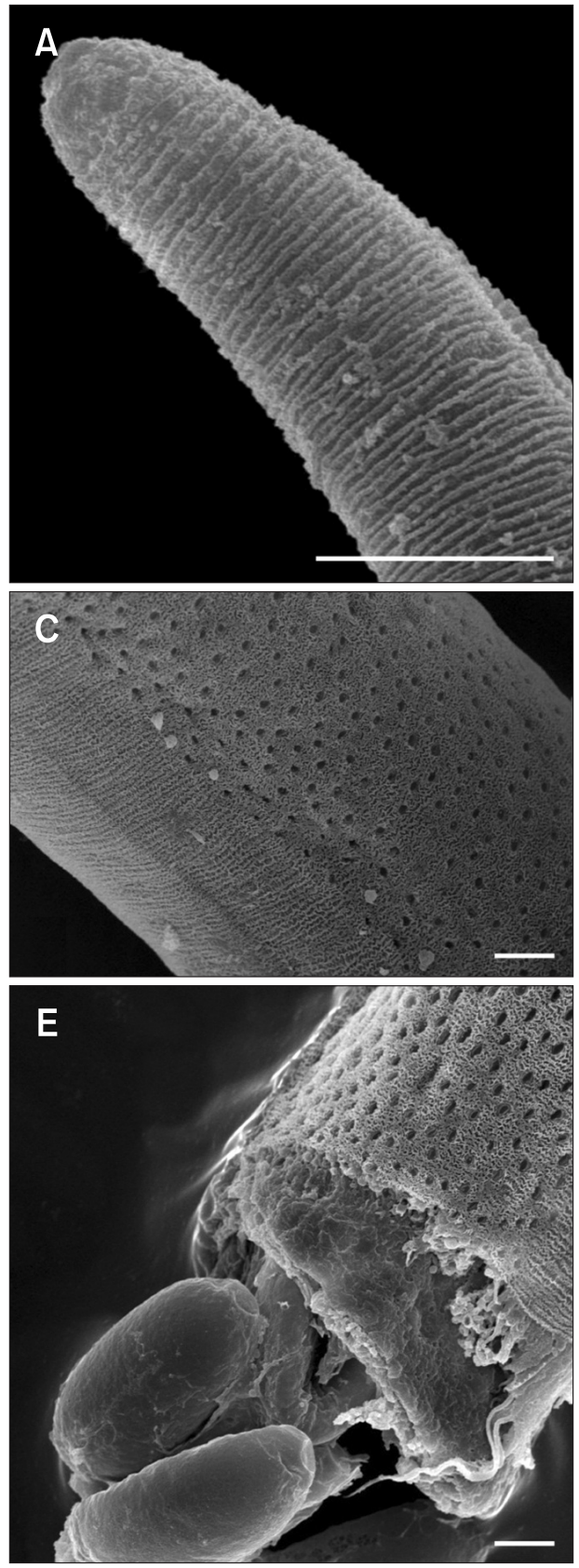
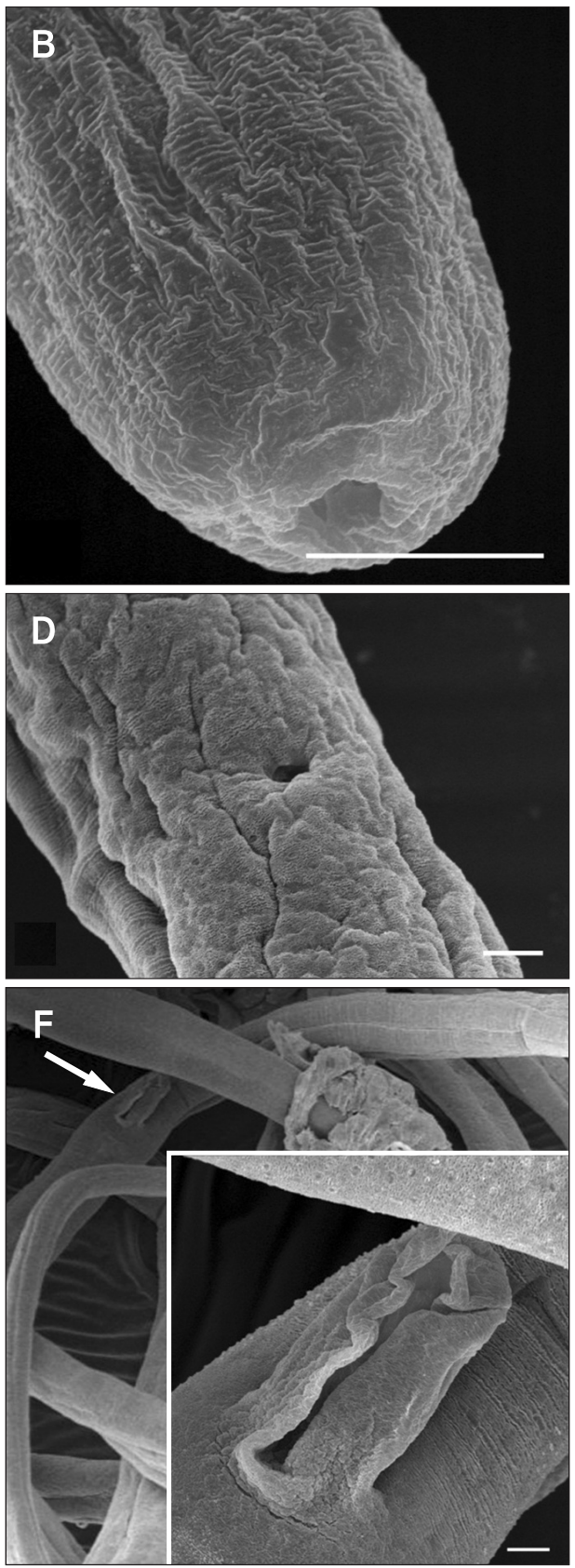

Fig. 5. Scanning electron micrograph of female Capillaria hepatica. It showed anterior (A), posterior (B), and mid region (C F) of isolated female C. hepatica. (A) Anterior region with transverse striations was most thin in the worm. (B) Excretory pore (anus) observed in the end of the worm. (C) A pair of bacillary bands situated in the mid region of the worm. (D) Vulva was a pore-like structure situated on the ventral region. (E) Eggs, epithelial tissue and muscle fibers observed in the mid region of fragmented worm. (F) Postvulval uterine sac (egg sac) projected from the worm (arrow and enlarged inset). Scale bars $=10 \mu \mathrm{m}$. 
distributed on the ventral part of the worm (Fig. 5D). Occasionally, the fragment of $C$. hepatica was observed. In this section, the internal organs such as cuticle layers, uterus containing eggs were observed. Epithelial tissues and muscle fibers were included in the surface of the cuticle (Fig. 5E). An ovipositor was seen to project out from the worm (Fig. 5F). In male $C$. hepatica, the anterior region was similar to that of female counterpart, which was tapered to a rounded anterior end (Fig. 6A). The width of anterior region, posterior, and mid region was $31.13 \mu \mathrm{m}$ (Fig. 6A), $50.16 \mu \mathrm{m}$ (Fig. 6B), and $60.74 \mu \mathrm{m}$ (Fig. 6C), respectively. Mid region of the male worm had a pair of bacillary bands with bacillary pore located on the surface of the worm (Fig. 6C). Several different characteristics were observed in the spicule and spicular sheath. The spicular sheath had a tubule with each different length and the surface was corrugated with transverse striations. Spicular sheath was folded like the wrinkled straw (Fig. 6D) and was protruded about $100 \mu \mathrm{m}$ from the posterior end (Fig. 6E). In other case, the spicular sheath had approximately $46 \mu \mathrm{m}$ in length and spicule projected approximately $6 \mu \mathrm{m}$ from the end of sheath (Fig. 6F). In addition, a particular morphological feature of spicular sheath was noted. When we observed the lateral side,
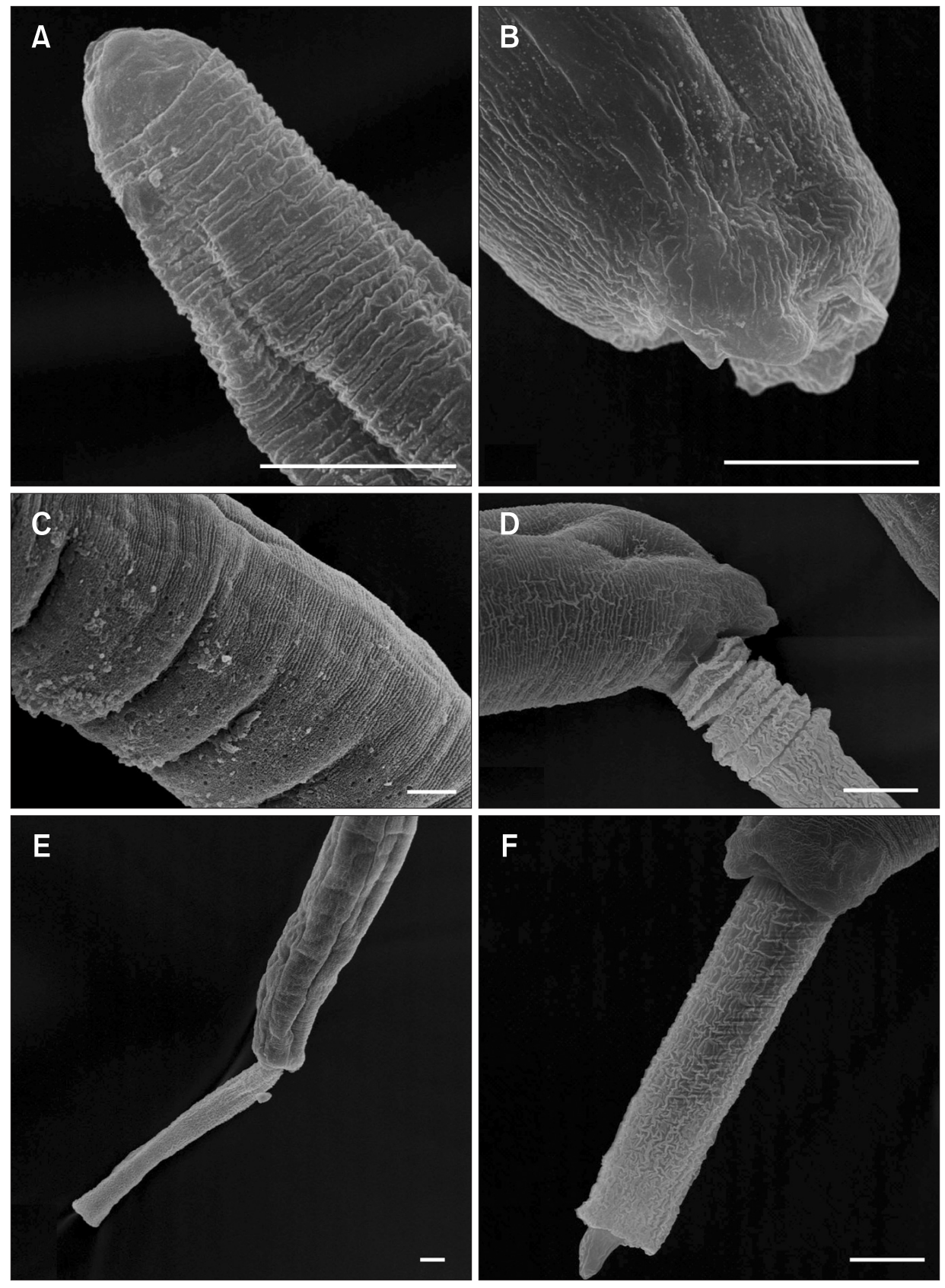

Fig. 6. Scanning electron micrograph of male Capillaria hepatica. It showed anterior (A), posterior (B), mid region (C) and spicule of isolated male $C$. hepatica (D F). (A) Anterior region with transverse striations was most thin of the worm. (B) Posterior region of the male worm which was not exist spicule and spicular sheath. (C) A pair of bacillary bands was situated on the mid region. Spicule and spicular sheath had several form in posterior end of male worm. (D) Partially wrinkled spicular sheath was adjacent to the posterior end. (E, F) Spicular sheath had tubular structure and transverse striations. Scale bars $=10 \mu \mathrm{m}$. 
the angle of the posterior end from the region with a spicule was approximately 110 to 120 degrees (Fig. 6B-F).

\section{DISCUSSION}

C. hepatica is a parasitic nematode living in the liver of rodents and other mammals, such as lagomorphs, dogs, cattle, and humans. Rat species of the genus Rattus are the primary host and natural reservoir of $C$. hepatica. However, infection to other mammals occurs due to ingestion of water or food contaminated with the embryonated C. hepatica eggs (Roberts et al., 1996; Spratt \& Singleton, 2001). The Norway rat, $R$. norvegicus, and the black rat, Rattus rattus, are common and widely distributed rodent species. In Korea, almost all reports of $C$. hepatica infection have been in Norway rat $R$. norvegicus (Lee, 1964; Seo et al., 1964; Min, 1979; Seong et al., 1995; Jeong et al., 2008).

The genus Capillaria includes approximately 300 species of which four of them (C. philippinensis, C. aerophila, C. plica, and C. hepatica) has been found in humans (Spratt \& Singleton, 2001; Lloyd et al., 2002; Ruas et al., 2003; Nakamura, 2005; Mowat et al., 2009). Although the width and length of each nematode varies, gross biological structures and shape are similar among the worms of the same genus. However, the differences of size, structures, and distribution are noted among the worms of different species.

Previous reports showed that the length of male and female C. hepatica was about 15 to $37 \mathrm{~mm}$ and 52 to $104 \mathrm{~mm}$, respectively (Luttermoser, 1938; Neva \& Brown, 1994; Sun, 1999). Adult $C$. hepatica, measured 88 to $154 \mu \mathrm{m}$ in the diameter has a genital tube, an intestinal tract, and other external structure of the class Enoplea (adenophorea, aphasmidea) such as stichosomes and two bacillary bands (Kim et al., 2009; Resendes et al., 2009).

In this study, the male and female worms were measured about $36.92 \mathrm{~mm}$ long and 23 to $59 \mu \mathrm{m}$ wide and $69.6 \mathrm{~mm}$ long and 28 to $124 \mu \mathrm{m}$ wide, respectively (Table 1). The values

Table 1. Body length and width of Capillaria hepatica isolated from mouse livers at 3 weeks after inoculation of embryonated eggs

\begin{tabular}{clcc}
\hline Data set & \multicolumn{1}{c}{ Region } & Male $(\mathrm{n}=5)$ & Female $(\mathrm{n}=5)$ \\
\hline \multirow{2}{*}{ Length } & Total $(\mathrm{mm})$ & $36.92 \pm 11.94$ & $69.60 \pm 10.81$ \\
& Spicule $(\mu \mathrm{m})$ & $446.80 \pm 77.97$ & - \\
& Spicular sheath $(\mu \mathrm{m})$ & $246.49 \pm 39.43$ & - \\
\multirow{5}{*}{ Width } & Anterior part $(\mu \mathrm{m})$ & $31.13 \pm 2.97$ & $24.68 \pm 1.67$ \\
& Mid part $(\mu \mathrm{m})$ & $60.74 \pm 2.29$ & $84.26 \pm 2.21$ \\
& Posterior part $(\mu \mathrm{m})$ & $50.16 \pm 2.32$ & $71.23 \pm 3.27$ \\
& spicule $(\mu \mathrm{m})$ & $6.08 \pm 0.62$ & - \\
& Spicular sheath $(\mu \mathrm{m})$ & $10.59 \pm 0.88$ & - \\
\hline
\end{tabular}

Values are presented as mean \pm standard deviation. were similar to those in other reports. This worm also showed the typical characteristics of $C$. hepatica such as several genital organs including a genital tube containing eggs in the female worms.

C. hepatica has a capillary-like (slender-shaped) structure with a narrow anterior part (7 to $10 \mu \mathrm{m})$, and the posterior part is gradually thicker. Female worms have a length of 27 to $100 \mathrm{~mm}$ and a width of 0.1 to $0.89 \mathrm{~mm}$ whereas male worms are smaller with 15 to $50 \times 0.04$ to $0.1 \mathrm{~mm}$ (Schmidt, 2001).

The anterior region of $C$. hepatica was less than $10 \mu \mathrm{m}$ and gradually thicker from the anterior end. Mid region of the female worm was about $84.26 \mu \mathrm{m}$ thick and had a pair of bacillary bands with bacillary pore located on the surface of the worm. Mid region of male worm was $60.74 \mu \mathrm{m}$ thick and had a pair of bacillary bands with bacillary pore located on the surface of the worm.

C. hepatica eggs found in the host liver are barrel-shaped and unembryonated, with typical bipolar plugs and prominent radial striations in the outer layer of the shell, and also have a dark middle layer of shell between two colorless layers (Beaver et al., 1984). They were measured 21 to $31 \mu \mathrm{m}$ wide and 40 to $54 \mu \mathrm{m}$ long (Wright, 1961; Zaman \& Keong, 1995; Resendes et al., 2009). When we observed the isolated C. hepatica using SEM, we can find several genital organs and eggs in the female worm such as vulva and several shapes of spicule and spicular sheath in the male worm. In the female worm, vulva was observed as posterior ventral part of the worm. Eggs measured $55 \mu \mathrm{m}$ long and $31 \mu \mathrm{m}$ wide were contained in the genital tube, but they did not exist in liver parenchyma of the mouse.

In the male genital organ, a single spicule and spicular sheath were seen. A single spicule was projected from the posterior end of the worm. However, it was occasionally located in the inner-cavity of the worm. The spicule was thin, long, and string-like in shape and was $446 \mu \mathrm{m}$ long and $6 \mu \mathrm{m}$ wide. The spicular sheath was tubular with a corrugated surface and transverse striations. Male nematodes usually have one or two spicules for reproduction (Zaman \& Keong, 1995), although Order Trichurida have one spicule (Roberts et al., 1996) and Order Spirurida have two spicules (Mutafchiev \& Georgiev, 2008; Smales et al., 2009). Order Trichurida Capillaria philippinensis from the human intestine have smooth and well-sclerotized spicules of 411 to $468 \mu \mathrm{m}$ in length and 3 to $12 \mu \mathrm{m}$ in width (Moravec, 2001).

These results show that the external structure of $C$. hepatica was similar to that of other species in genus Capillaria. By contrast, the body length and spicule size was longer than that of other species in genus Capillaria. The body length of male C. hepatica was 19 to 27 times longer than that of male $C$. philippinensis and the body length of female $C$. hepatica was 10 to 17 times longer than female C. philippinensis. Spicule length was approximately 1.6 times longer than that of $C$. 
philippinensis. The length and width of the isolated C. hepatica were approximately 10 to 20 times longer than those of other species in the genus Capillaria (Chitwood et al., 1968).

C. hepatica has a short life cycle within approximately 40 to 60 days (Luttermoser, 1938; Wright, 1961). Adult C. hepatica sexually matures in the liver parenchyma and is able to mate approximately 15 to 20 days post-infection. In case of mouse, sexually matured males are found in the livers at 15 to 18 days post-infection and the females are found at 15 to 20 days post-infection. Eggs are produced from the fertilized female worm at 18 to 33 days post-infection (Luttermoser, 1938; Wright, 1961; Sun, 1999). C. hepatica eggs become infective in about 45 to 60 days (Campbell, 1991). In particular, those eggs are not released from the liver and develop to the eightcell stage, until the death of the host (Juncker-Voss et al., 2000; Schmidt, 2001). This is why we have conducted an experiment at 3 weeks after infection, because this time is appropriate to examine genital organs such as spicule, spicule sheath, vulva and eggs.

Our results suggest that spicule and egg formation may occur about 3 weeks after experimental infection. These results are consistent with previous reports that $C$. hepatica may mature within 18 to 29 days after infection (Spratt \& Singleton, 2001). This study was designed to observe the fine structure of $C$. hepatica through isolation of undamaged whole worms. Female $C$. hepatica dies immediately after laying eggs in the liver. Autopsy specimens show a histologically different pattern of disease. Early, immature worms, granulomas, and eosinophilic infiltration are evident. Later, the adult worms can be identified with numerous mixed eggs. The latter stages are characterized by the lack of adult worms, the presence of viable eggs, and marked fibrosis (Gutierrez, 2006). Because the worms are "walled off" after laying eggs and death, most reports are limited to observation of embedded C. hepatica or pathological findings as case reports. Although understanding of the inner structure and the hepatic symptoms caused by C. hepatica was relatively well known, it is difficult to find the external structure and special organ structure because of this parasitic life cycle. Therefore, we have isolated 10 whole $C$. hepatica worms without damage from the liver of laboratory mouse at 3 weeks after inoculation of artificially embryonated eggs collected from house rats ( $R$. norvegicus). We were able to report the characteristics and fine structures of the undamaged $C$. hepatica through light and SEM. These results can be useful for further studies on the morphology of nematodes including $C$. hepatica.

\section{SUMMARY}

C. hepatica was isolated without damage from the liver of the laboratory mice at 3 weeks after inoculation of artificially embryonated eggs collected from house rats ( $R$. norvegicus). Detailed characteristics and fine structures of the undamaged C. hepatica were presented. The length of the isolated female and male $C$. hepatica was approximately $69.60 \mathrm{~mm}$ and 36.92 $\mathrm{mm}$, respectively. In addition, the ultrastructure of the $C$. hepatica, including bacillary band, eggs and vulva in female and spicule and spicule sheath in male C. hepatica was also described.

\section{REFERENCES}

Anderson R C (2000) Nematode Parasites of Vertebrates. Their Development and Transmission, 2nd ed., pp. 612-614, (CABI Publishing, Wallingford).

Bancroft T L (1893) On the with-worm of the rats liver. J. Proc. R. Soc. New S. Wales. 27, 86-90.

Beaver P C, Jung R C, and Cupp E W (1984) Clinical Parasitology, pp. 231-252, (Lea \& Febiger, Philadelphia).

Campbell B G (1991) Trichuris and other Trichinelloid nematodes of dogs and cats in the United States. Compend. Contin. Educ. Pract. Vet. 13, 769-778.

Ceruti R, Sonzogni O, Origgi F, Vezzoli F, Cammarata S, Giusti A M, and Scanziani E (2001) Capillaria hepatica infection in wild brown rats (Rattus norvegicus) from the urban area of Milan, Italy. J. Vet. Med. B 48, 235-240.

Chitwood M B, Valesquez C, and Salazar N G (1968) Capillaria philippinensis sp. n. (Nematoda: Trichinellida), from the intestine of man in the Philippines. J. Parasitol. 54, 368-371.

Choe G, Lee H S, Seo J K, Chai J Y, Lee S H, Eom K S, and Chi J G (1993) Hepatic capillariasis: first case report in the Republic of Korea. Am. J.
Trop. Med. Hyg. 48, 610-625.

Claveria F G, Causapin J, de Guzman M A, Toledo M G, and Salibay C (2005) Parasite biodiversity in Rattus spp caught in wet markets. Southeast Asian J. Trop. Med. Public Health 36(Suppl 4), 146-148.

Farhang-Azad A (1977) Ecology of Capillaria hepatica (Bancroft 1893) (Nematoda). 1. Dynamics of infection among Norway rat populations of the Baltimore zoo, Baltimore, Maryland. J. Parasitol. 63, 117-122.

Fuehrer H P, Igel P, and Auer H (2011) Capillaria hepatica in man-an overview of hepatic capillariosis and spurious infections. Parasitol. Res. 109, 969-979.

Gutierrez Y (2006) Other tissue nematode infection by Yezid. In: Tropical Infectious Diseases, eds. Guerrant R L, Walker D H, and Weller P F, pp. 1242-1243, (Elsevier, Philadelphia).

Jeong W I, Do S H, Hong I H, Ji A R, Park J K, Ki M R, Park S C, and Jeong K S (2008) Macrophages, myofibroblasts and mast cells in a rat liver infected with Capillaria hepatica. J. Vet. Sci. 9, 211-213.

Juncker-Voss M, Prosl H, Lussy H, Enzenberg U, Auer H, and Nowotny N (2000) Serological detection of Capillaria hepatica by indirect immunofluorescence assay. J. Clin. Microbiol. 38, 431-433. 
Kim D K, Joo K H, and Chung M S (2007) Changes of cytokine mRNA expression and IgG responses in rats infected with Capillaria hepatica. Korean J. Parasitol. 45, 95-102.

Kim S J, Min B H, Lee H S, Lee B W, and Joo K H (2009) Ultrastructure of the integument of Capillaria hepatica (syn. Calodium hepatica). Korean J. Microscopy 39, 167-173.

Kohatsu H, Zaha O, Shimada K, Chibana T, Yara I, Shimada A, Hasegawa $\mathrm{H}$, and Sato $\mathrm{Y}$ (1995) A space-occupying lesion in the liver due to Capillaria infection. Am. J. Trop. Med. Hyg. 52, 414-418.

Lee C W (1964) The experimental studies on Capillaria hepatica. Kisaengchunghak Chapchi 2, 63-80.

Lloyd S, Elwood C M, and Smith K C (2002) Capillaria hepatica (Calodium hepaticum) infection in a British dog. Vet. Rec. 151, 419-420.

Luttermoser G W (1938) An experimental study of Capillaria hepatica in the rat and the mouse. Am. J. Trop. Med. Hyg. 27, 321-340.

McQuown A L (1950) Capillaria hepatica: report of genuine and spurious cases. Am. J. Trop. Med. 30, 761-767.

Min H K (1979) Prevalence of Capillaria Hepatica among house rat in Seoul. Kisaengchunghak Chapchi 17, 93-97.

Moravec F (2001) Redescription and systematic status of Capillaria philippinensis, an intestinal parasite of human beings. J. Parasitol. 87, 161-164.

Mowat V, Turton J, Stewart J, Lui K C, and Pilling A M (2009) Histopathological features of Capillaria hepatica infection in laboratory rabbits. Toxicol. Pathol. 37, 661-666.

Mutafchiev Y and Georgiev B B (2008) A new acuariid nematode, Syncuaria mackoi n. sp. (Spirurida), from Ciconianigra (L.) (Ciconiiformes: Ciconiidae) in Europe. Syst. Parasitol. 70, 71-79.

Nabi F, Palaha H K, Sekhsaria D, and Chiatale A (2007) Capillaria hepatica infestation. Indian Pediatr. 44, 781-782.

Nakamura N (2005) Parasitic lesions of bovine liver attributed to Capillaria species. J. Comp. Pathol. 132, 228-231.

Neva F A and Brown H W (1994) Basic Clinical Parasitology, 6th ed., pp. 150-151, (Prentice Hall International, London).

Resendes A R, Amaral A F, Rodrigues A, and Almeria S (2009) Prevalence of Calodium hepaticum (Syn. Capillaria hepatica) in house mice
(Musmusculus) in the Azores archipelago. Vet. Parasitol. 160, 340343.

Roberts L S, Janovy J, Schmidt G D, and Larry S (1996) Roberts' Foundations of Parasitology, 5th ed., pp. 87-88, 385, (Wm C. Brown Publishers, Dubuque).

Ruas J L, Soares M P, Farias N A R, and Brum J G W (2003) Capillaria hepatica infection in wild carnivores (Lycalopex gymnocercus and Cerdocyon thous) in southern Rio Grande Do Sul, Brazil. Arq. Inst. Biol. 70, 127-130.

Schmidt S (2001) Investigation on the occurrence of Capillaria hepatica and metacestodes of Cyclophillida in wild mice in Germany, pp. 145, PhD Thesis, University of Leipzig.

Seo B S, Rim H J, Lee C W, and Yoon J S (1964) Studies on the parasitic helminths of Korea: II. parasites of the rat, Rattus norvegicus Erxl. in Seoul, with the description of Capillaria hepatica (Bancroft, 1893) Travassos. Kisaengchunghak Chapchi 2, 55-62.

Seong J K, Huh S, Lee J S, and Oh Y S (1995) Helminths in Rattus norvegicus captured in Chunchon, Korea. Korean J. Parasitol. 33, 235-237.

Singleton G R, Spratt D M, Barker S C, and Hodgson P F (1991) The geographic distribution and host range of Capillaria hepatica (Bancroft) (Nematoda) in Australia. Int. J. Parasitol. 21, 945-957.

Smales L R, Harris P D, and Behnke J M (2009) A redescription of Protospirura muricola Gedoelst, 1916 (Nematoda: Spiruridae), a parasite of murid rodents. Syst. Parasitol. 72, 15-26.

Spratt D M and Singleton G R (2001) Hepatic capillariasis. In: Parasitic Disease of Wild Mammals, eds. Samuel W M, Pybus M J, and Kocan A A, pp. 365-379, (lowa State University Press, Ames).

Sun T (1999) Parasitic Disorders: Pathology, Diagnosis, and Management, 2nd ed., pp. 185-189, (Lippincott Williams and Wilkins, Baltimore).

Wright K A (1961) Observations on the life cycle of Capillaria hepatica (Bancroft, 1893) with a description of the adult. Can J. Zool. 38, 167182.

Zaman V and Keong L A (1995) Handbook of medical parasitology. In: Introduction to Nematodes, 3rd ed., pp. 167, 230-231, (KC Ang Publishing, Singapore). 